\title{
A Study of Gender Differences of Attitudes toward Date Rape among Chinese University Students
}

\author{
Peitzu Lee*, He Kaiwen, Deng Jiayi
}

Copyright $\mathrm{C} 2018$ by authors, all rights reserved. Authors agree that this article remains permanently open access under the terms of the Creative Commons Attribution License 4.0 International License

\begin{abstract}
The purpose of this study was to investigate differences in attitudes towards date rape between genders in Mainland Chinese university students, given the fact that there is little research about attitudes toward date rape, which is defined as the occurring of forcible intercourse between two parties in romantic or potentially sexual relationship, among Chinese people. 104 male and 117 female university students, aged from 17 to 27 were asked to complete the Attitudes towards Forcible Date Rape (FDR) Scale online. The findings showed that female students rejected date rape-tolerant attitudes more than their male counterparts. Also, female students expressed more disagreement with the belief that forcible intercourse on a date is acceptable under certain conditions, compared to the male students. The current findings suggest that there is indeed a need for education concerning consent versus rape in mainland China.
\end{abstract}

Keywords Attitude toward Date Rape, Gender Difference, Chinese University Students

\section{Introduction}

Although the publics' recognition of rape has grown, date rape is still one of the most frequent events in China which remains unrecognized and undocumented. In China, date rape is seldom regarded as a form of criminal sexual assault, and only a small number of women would report their experiences if they were raped. There are many existing studies that focus on general rape instead of date rape in particular.

Current studies utilized university students as participants to demonstrate gender differences on the attitude toward rape, including Turkish [1], Koreans [2] and Americans $[3,4,5,6,7,8]$. Different attitudes toward rape between males and females are significant. Studies have shown that men and women perceived each other's body language or behaviors differently. An experiment conducted by Abbey [3] indicated that males are more likely to interpret people's intentions with a sexual lens. Also, Muehlenhard [4,7] suggested that men overestimate their dates' sexual interest more often than women do. Moreover, males are less likely to judge the scenarios where coercive intercourse take place while dating as date rape compared to females $[7,8,9]$.

Thus, the Attitudes towards Forcible Date Rape (FDR) scale was employed in this study to investigate gender differences of male and female's attitudes toward date rape among Chinese college students. The results showed that there were significant gender differences of Chinese students' attitude toward date rape. The findings from this study showed valuable evidences that there was indeed a need for education regarding sexual relations in order to reduce date rape in mainland China.

\section{Literature Review}

\subsection{What is Date Rape?}

Legislation has struggled to pin down a definition of rape. In California, rape is defined as "an act of sexual intercourse...accomplished against a person's will by means of force, violence, duress, menace, or fear of immediate and unlawful bodily injury on the person or another" [10]. In other words, rape includes two elements which are the force from the attackers and the nonconsenting of the victim, under the law of rape in California and 7 other states in the United States [10]. Consent refers to the agreement made under the "degree of freedom and capacity", though it is still vague when we try to determine "whether 'no' really means no" [11]. Due to many factors regarding consent (body language, alcohol, etc.) make understanding what and how consent takes place difficult, and up for interpretation, the effectiveness of explicit words or actions of nonconsenting is left open $[7,11]$.

Date rape is a form of acquaintance rape which refers to the rape occurs between the two parties who know each other [12]. The lack of a comprehensive definition of date 
rape requires research in its field. The research of Verbery, Wood, Desmarais and Senn [13] concluded 4 elements of date rape: sexual intercourse, lack of consent, force or forced, and between dating partners. According to the definition of "date" in Oxford Dictionary, a date is "a social or romantic appointment or engagement". In other words, dating partners are not limited to the people who are romantic involved, but it also includes those in potential sexual relationships.

\subsection{Common Rape Myth}

The misunderstandings about rape are always categorized as rape myths or rape scripts. More ex-plicitly, rape myth is most commonly defined as "prejudicial, stereotyped, or false beliefs about rape, rape victims, and rapists" [14] or as "attitudes and beliefs that are generally false but are widely and persistently held, and that serve to deny and justify male sexual aggression against women" [15]. According to Peterson and Muehlenhard [16], there are two common contents of rape myths that exist in research. One is defining rape much more narrowly than licit definition. This includes the definition of perpetrator (e.g., "woman would never be raped by her boyfriend"), the victim (e.g., "only certain women who do things like getting drunk or dressing suggestively are raped"), the location the rape occurred (e.g., "rape almost never happens in a woman's own home"), and the degree of violence and physical resistance that occurred during the rape (e.g., "if a woman doesn't physically resist sex - even when protesting verbally - it really can't be considered rape") $[16,17]$. The other is rape myths blaming the victim for rape. This includes reproaching women for their flirting behaviors, lacking clearly communications and letting things getting out of control [18]. However, ac-cording to [15], two most common thoughts about rape myths are that only bad women are raped and that women always tell lies about rape. In Lee, Busch, Kim and Lim's [2] study of date rape myth, in Korea, people hold the idea that whether a woman deserves legal protection depends on his sexual history and a woman who lost her chastity does not deserve legal protection after suffering from date rape.

\subsection{Gender Differences in Attitude toward Date Rape}

There are various researches that reveal that there is a significant difference between attitudes of males and females toward date rape. From Anderson, Cooper and Okamura's [19] meta-analytic review of attitudes towards date rape, men accepted date rape more than women. Due to males predisposed notions of date rape, men tended to perpetrate more accepting attitudes, while females' rape acceptance was related to their sexual experience. For university students, according to Lee et al.'s [2] study, among university students in South Korea, date-rape supportive attitudes were more received by male students than female students, and female students were more rejecting of the thoughts that using force to make sex occur when dating was acceptable in certain circumstances. Also, date rape-supportive attitudes were more likely to be held by males than females [20] and when date rape happens, males always blamed the woman more than females did [21]. For high school students, female students blamed the raped woman less then male students did and believed less strongly about rape myth than male students did [22].

\subsection{Date Rape in China}

Research on comparing Asian and non-Asian people's attitude toward rape have indicated the significant differences across gender and ethnicity, where "Asian students were more tolerant of rape myth" $[23,24,25]$. On the legislative level, the judicial cognizance of date rape has been widely discussed $[26,27,28]$. However, on the psychological level, the research of date rape is missing among Chinese literatures. Some articles which originally written in English about the emergence of date rape have been translated into Chinese and published on Chinese periodical $[29,30]$. The lack of data from Chinese population increased the interest of research on date rape. Zhou and Zheng [31] summarized the cognitions of date rapists, similar to the rapists in general, in a systematic overview which included "rape-supportive beliefs (such as rape myth), "belief about masculinity", "sexual fantasy", and "sexual script" [31].

\section{Methodology}

\subsection{Participants}

This study recruited 221 participants including undergraduates and postgraduates, aged from 17 to 27 $(\mathrm{M}=20.8 ; \mathrm{SD}=1.65)$, from mainland China. The response rate of the scale is 100 percent. Among 221 participants, $47.1 \%$ were males $(\mathrm{n}=104)$ and $52.9 \%$ were females $(\mathrm{n}=117) .8 .1 \%$ of the respondents $(\mathrm{n}=18)$ were in a period having a thing, $38.5 \%$ of the respondents $(n=85)$ were in romantic relationships, and $53.4 \%$ of the respondents $(\mathrm{n}=116)$ were single. The age range in this study was from 17 to 27 , and the average age was $20.8(\mathrm{SD}=1.65)$.

\subsection{Procedure}

The surveys were distributed online through the survey website called Sojump. The participants voluntarily completed the informed consent and the Chinese version survey called Attitudes toward Forcible Date Rape (FDR) scale which was developed by Fischer and Chen in 1994 [32].

\subsection{Instrument}

The Attitudes towards Forcible Date Rape (FDR) scale

The FDR scale was used to estimate the attitude toward 
date rape. Reliability and validity have been proved satisfactory on the congeneric true score model [32]. The scale contains a vignette (a date rape scenario was presented) and 9 separated 5-Likert scale comprising conditions, for example, "he had spent a lot of money on her", "she had gotten him sexually excited", and "she let him touch her breasts", which ask how acceptable the male's behavior was under a specific condition [32].

\section{Development of the Chinese version of the FDR scale}

Attitudes of males and females toward date rape among Chinese university students were investigated by using Aattitudes toward Forcible Date Rape (FDR) scale in Chinese version. This research used the Chinese version scale to collect data. SPSS (Statistical Product and Service Solutions) was employed to complete the data analysis.

In order to keep the integrity of the FDR scale, no item was eliminated during the translation. All items were translated without losing the author's original intention by using the popular Chinese vocabulary and meanings which were easy to be understood by participants. In terms of reliability of the Chinese version of FDR scale, internal consistency was utilized, and the Cronbach's $\alpha$ is 0.864 . Content Validity Index (CVI), which also called Expert Validity Index, was used to test the validity of the Chinese version of FDR scale. Four bilingual experts in the field of social psychology were invited to examine the content validity of the Chinese version of FDR scale, and the value of CVI is 0.85 , which met the requirements of CVI value (equal to or over 0.8 ) [33]. Reliability and validity of the Chinese version of FDR scale have been proved satisfactory.

\section{Results}

According to Fischer and Chen [32], there are 9 scenarios in the Attitudes toward Forcible Date Rape (FDR) scale. The results of this study (see Appendix) showed that there were significant differences of attitudes toward forcible intercourse between males and females under eight out of nine conditions (items), and under one condition (item) they kept identical attitude. The eight conditions are: item 2 "she had gotten him sexually excited", $t(156)=$ $-4.110, p=.000$; item3 "she let him touch her breasts", $\mathrm{t}(156)=-3.940, \mathrm{p}=.000$; item 4 "they had dated each other for a long time", $\mathrm{t}(156)=-3.847, \mathrm{p}=.000$; item5 "she was drunk", $\mathrm{t}(156)=-2.987, \mathrm{p}=.000$; item 6 "she was going to have intercourse with him and then changed her mind", $\mathrm{t}(156)=-5.813, \mathrm{p}=.000$; item7 "she had intercourse with other males", $\mathrm{t}(156)=-4.110, \mathrm{p}=.003$; item8 "she led him on", $\mathrm{t}(156)=-2.530, \mathrm{p}=0,012$; item 9 "he was so sexually excited he could not stop", $t(156)=-3.610, p=.000$. These results suggest that gender differences of the attitudes toward date rape between males and females do exist. Specifically, male participants were more likely to tolerate the occurrence of coercive intercourse than the counterparts under certain conditions, except item1 "spend[ing] a lot of money on her", t (156) $=-1.674$, p $=.096$.

Item 7 has the highest score for both males $(\mathrm{M}=4.26$, $\mathrm{SD}=0.99)$ and females $(\mathrm{M}=4.80, \mathrm{SD}=0.63)$, which means that both male and female Chinese university students most reject the use of force to have intercourse on a date under the given situation, "if she was drunk"; item 10 has the lowest score for both males $(\mathrm{M}=2.27, \mathrm{SD}=1.21)$ and females $(\mathrm{M}=2.74, \mathrm{SD}=1.30)$, which means that both male and female Chinese University students least reject the use of force to have intercourse on a date under the given situation, "if she led him on".

\section{Discussion}

The purpose of this study was to investigate the attitude towards date rape among university students in Mainland China. From the mean scores, under nine situations in the Attitudes towards Forcible Date Rape scale, male students showed higher tolerance of using coercive intercourse than the counterpart under eight conditions, but both male and female students tended to consider that money was not a reasonable trigger of the utilization of forcible intercourse. This finding was consistent with similar previous studies investigating the populations of Asian and non-Asian university students, including Koreans and Americans, proposing that the attitudes toward date rape were remarkably different between male and female university students $[2,23,24,25,32,34]$. Aside from this, this study indicated that male students showed more acceptance of using force to initiate intercourse under certain situations during dates compared to female students, which replicated the results of the studies employing population in different ethnic groups [2, 32]. On one hand, a lack of sexual education provided by society, the family, or the schools in mainland China might contribute to this confusion and gender imbalance on labeling forcible intercourse as rape under any conditions. Moreover, "traditional gender role beliefs" accessed through socialization and "adversarial sexual beliefs" from pornographic material were predictable factors of rape acceptance [19]. On the other hand, Johnson [35] declared that money spent had insignificant impact on the emergence of date rape. The liberation of women has increased the possibility of female independence, which created a state of economic equality between men and women nowadays. Therefore, "financial investment" could no longer whitewash the evil of forcible intercourse.

A potential limitation of this study was that the results can only be implicated within university students aged 17 to 27 years old. Exploring different populations and investigating the causes of gender differences of attitudes toward rape are suggested for further research, which might give a glimpse into the role of culture and awareness level. In spite of the limitation, the findings of this study 
presented the current situation of attitudes differences toward date rape among Chinese university students, which was lacking in literature, and these findings possessed significant implications of a needed program to raise the awareness of potential sexual assault and to educate people about date rape among university students in mainland China. Moreover, these findings could be also applied in sexual related education and sexual assault prevention systems.

\section{Conclusions}

The result of this study found that under eight out of nine conditions (items), there existed significant differences of attitudes toward coercive intercourse between male and female university students, and only under one condition (item), they kept identical attitude. In summary, the significant gender differences of attitudes toward date rape existed among university students in mainland China. Considering that the gender differences in the attitudes of date rape among Chinese university students was highlighted by the present study, increasing targeted awareness, prevention and intervention strategies based on a sexual related education to reduce date rape problem are recommended.

\section{Appendix}

Table 1. Independent-sample t-test for gender differences from item1 to 9

\begin{tabular}{|c|c|c|c|c|c|c|}
\hline & \multicolumn{2}{|c|}{$\begin{array}{c}\text { Male } \\
(n=104)\end{array}$} & \multicolumn{2}{|c|}{$\begin{array}{l}\text { Female } \\
(\mathrm{n}=117)\end{array}$} & \multirow[b]{2}{*}{$t$} & \multirow[b]{2}{*}{$p$} \\
\hline & $M$ & $S D$ & $M$ & $S D$ & & \\
\hline Item 1 & 4.04 & 1.127 & 4.33 & 1.063 & -1.674 & 0.096 \\
\hline Item 2 & 3.82 & 1.258 & 4.53 & 0.856 & -4.110 & $0.000 * *$ \\
\hline Item3 & 2.27 & 1.267 & 3.05 & 1.232 & -3.940 & $0.000 * *$ \\
\hline Item4 & 2.90 & 1.393 & 3.72 & 1.282 & -3.847 & $0.000 * *$ \\
\hline Item5 & 4.26 & 0.991 & 4.80 & 0.633 & -4.094 & $0.000 * *$ \\
\hline Item6 & 3.17 & 1.245 & 4.18 & 0.905 & -5.813 & $0.000 * *$ \\
\hline Item7 & 3.94 & 1.241 & 4.46 & 0.916 & -2.987 & $0.003 * *$ \\
\hline Item8 & 2.23 & 1.210 & 2.74 & 1.300 & -2.530 & $0.012^{*}$ \\
\hline Item9 & 3.98 & 1.396 & 4.64 & 0.844 & -3.610 & $0.000 * *$ \\
\hline
\end{tabular}

$* p<0.05, * * p<0.01$

Note. $\mathrm{M}=$ Mean. $\mathrm{SD}=$ Standard Deviation. 5-Likert Scale rang from definitely acceptable (1) to definitely unacceptable (5). 


\section{REFERENCES}

[1] Gölge ZB, Yavuz MF, Müderrisoglu S, Yavuz MS. Turkish University Students' Attitudes toward Rape. Sex Roles. 2003;49(11/12): 653-662.

[2] Lee J, Busch NB, Kim J, Lim H. Attitudes towards date rape among university students in South Korea. Sex Roles. 2007;57(9):641-649.

[3] Abbey A. Sex Differences in Attributions for Friendly Behavior: Do Males Misperceive Females' Friendliness?. Journal of Personality and Social Psychology. 1982;42(5):830-838.

[4] Muehlenhard CL. Misinterpreted Dating Behaviors and the Risk of Date Rape. Journal of Social and Clinical Psychology. 1988;6(1):20-37.

[5] Bostwick TD, Delucia JL. Effects of Gender and Specific Dating Behaviors on Perceptions of Sex Willingness and Date Rape. Journal of Social and Clinical Psychology. 1992;11(1):14-25.

[6] Marquart BS, Nannini DK, Edwards RW, Stanley LR, Wayman JC. Prevalence of Dating Violence and Victimization: Regional and Gender Differences. Adolescence. 2007;42(168):645-658

[7] Maurer TW, Robinson DW. Effects of Attire, Alcohol, and Gender on Perceptions of Date Rape. Sex Roles. 2008;58:423-434.

[8] Black KA, Gold DJ. Gender Differences and Socioeconomic Status Biases in Judgments about Blame in Date Rape Scenarios. Violence and Victims. 2008;23(1):115-130.

[9] Osman SL. Predicting men's rape perceptions based on the belief that "no" really means "yes." Journal of Applied Social Psychology. 2003;33:683-692.

[10] Lyon MR. No means no?: Withdrawal of consent during intercourse and the continuing evolution of the definition of rape. Journal of Criminal Law \& Criminology. 2004;95(1):277-314.

[11] Tadros V. Rape without Consent. Oxford Journal of Legal Studies. 2006;26(3):515-543.

[12] Nevid JS, Rathus SA, Greene B. Abnormal Psychology in A Changing World. 9th ed. The United State: Pearson Education; 2014. 397 p.

[13] Verbery N, Wood E, Desmarais S, Senn C. Gender differences in survey respondents' written definitions of date rape. The Canadian Journal of Human Sexuality. 2000;9(3):181-191.

[14] Burt MR. Cultural myths and supports for rape. Journal of Personality and Social Psychology. 1980;38(2):217.

[15] Lonsway KA, Fitzgerald LF. Rape myths: In review. Psychology of Women Quarterly. 1994;18(2):133-164.
[16] Peterson ZD, Muehlenhard CL. Was it rape? The function of women's rape myth acceptance and definitions of sex in labeling their own experiences. Sex Roles. 2004;51(3):129-144.

[17] Payne DL, Lonsway KA, Fitzgerald LF. Rape myth acceptance: Exploration of its structure and its measurement using the Illinois Rape Myth Acceptance Scale. Journal of Research in Personality. 1999;33(1):27-68.

[18] Hockett JM, Saucier DA, Badke C. Rape myths, rape scripts, and common rape experiences of college women: differences in perception of women who have been raped. Violence against Women. 2016;22(3):307-323

[19] Anderson KB, Cooper H, Okamura L. Individual differences and attitudes toward rape: A meta-analytic review. Personality and Social Psychology Bulletin. 1997;23(3):295-315.

[20] Holcomb DR, Holcomb LC, Sondag KA, Williams N. Attitudes about date rape: Gender difference among colleage students. College Students Journal. 1991;25(4):434-439.

[21] Osman SL, Davis CM. Predicting men's perceptions of date rape using the heuristic- systematic model. Journal of Sex Education and Therapy. 1997;22(3):25-32.

[22] Blumberg ML, Lester D. High school and college students' attitudes toward rape. Adolescence. 1991;26(103):727.

[23] Mori L, Bernat JA, Glenn PA, Selle LL, Zarate MG. Attitude toward Rape: Gender and Ethnic Differences across Asian and Caucasian College Students. Sex Roles 1995;32(7/8):457-468.

[24] Kennedy MA, Gorzalka BB. Asian and Non-Asian Attitudes toward Rape, Sexual Harassment, and Sexuality. Sex Roles. 2002;46(7/8):227-239.

[25] Lee J, Pomeroy EC, Yoo S, Rheinboldt K. Attitudes toward Rape A Comparison between Asian and Caucasian College Students. Violence against Women. 2005; 11(2):177-196.

[26] Wang L. 浅谈约会强奸的司法认定 (the Judicial Cognizance of Date Rape). 法制与社会 (Legal System and Society). 2012;7:128-129.

[27] Liu S. 法律视角下的约会强奸 (See Date Rape with Juristic Lens). 法律适用. 2005;232:44-48.

[28] Song P. 近关系强奸: 犯罪类型与司法认定的实证研究 (Acquaintance Rape: Criminal Types and Judicial Cognizance). Journal of Guizhou Police Office Vocational College. 2012:38-44.

[29] Ji L. 美国社交强奸风行 (the Prevalence of Date Rape in the United States). 北京成人教育 (Beijing Adult Education). 1996;3:47-48

[30] Ji L. 社交性强奸 (Date Rape). 东方养生 (Eastern Health Maintenance). 1996;3:24-25.

[31] Zhou H, Zheng Y. 强奸者认知特征 (Cognition of Rapists). Chinese Journal of Clinical Rehabilitation. 2006;10(34):148-153. 
[32] Fischer GJ, Chen J. The attitudes toward forcible data rape (FDR) scale: Development of measurement model. Journal of Psychopathology and Behavioral Assessment. 1994;16(1):33-51.

[33] Waltz CF, Strickland OL, Lenz ER. Measurement in nursing research. 2nd ed. Philadelphia: A. Davis; 1991.
[34] Fischer GJ. College student attitudes toward forcible date rape: I. Cognitive predictors. Archives of Sexual Behavior. 1986;15(6):457-466.

[35] Johnson KKP. Attributions about Date Rape: Impact of Clothing, Sex, Money Spent, Date Type, and Perceived Similarity. Family and Consumer Sciences Research Journal. 1995;23(3):292-310. 